\title{
COMPARING SVARS AND SEMS: TWO MODELS OF THE UK ECONOMY
}

\author{
JAN P. A. M. JACOBS ${ }^{\mathrm{a}}$ AND KENNETH F. WALLIS ${ }^{\mathrm{b} *}$ \\ a CCSO and Department of Economics, University of Groningen, The Netherlands \\ b Department of Economics, University of Warwick, UK
}

\section{SUMMARY}

The structural vector autoregression (SVAR) and simultaneous equation macroeconometric model (SEM) styles of empirical macroeconomic modelling are compared and contrasted, with reference to two models of the UK economy, namely the long-run structural VAR model of Garratt, Lee, Pesaran and Shin and the COMPACT model. Various styles of impulse response analysis are also compared and contrasted, and used to illustrate model properties. A 'reverse engineering' procedure is used to infer long-run relations of COMPACT comparable to the GLPS cointegrating relations. Copyright (c) 2005 John Wiley \& Sons, Ltd.

\section{INTRODUCTION}

Macroeconometric models of national economies and the global economy continuously develop and evolve, and different styles of model have emerged during this process. The oldest is the simultaneous equation macroeconometric model (SEM), sometimes associated with the names of Tinbergen and Klein, who inaugurated this style of analysis in the 1930s and 1940s. Sometimes this model is referred to as a structural econometric model, using the first adjective in the traditional Cowles Commission sense. This style of modelling has itself seen substantial development over time (as described, for example, by Wallis, 1995, 2000), often as a constructive reaction to critics, of whom the most notable were Lucas (1976) and Sims (1980), from different points of view. Responses to many of the criticisms are embodied in the contemporary SEMs maintained by monetary and fiscal policy agencies, research institutes and a few academic economists. Best known in the last group is Fair (http://fairmodel.econ.yale.edu) in the United States, while in the United Kingdom the originators of both the models used in the present study are academic researchers.

Sims (1980) argued that the structural identification of the then-existing SEMs was incredible. He proposed the alternative strategy of estimating unrestricted reduced forms, treating all variables as endogenous, namely vector autoregressive (VAR) models. The subsequent recognition that, for policy analysis, VAR models still require identifying assumptions (Cooley and LeRoy, 1985 , for example) resulted in a variety of ways of formulating such 'structural VAR' (SVAR) models, starting from Bernanke (1986), Blanchard and Watson (1986) and Sims (1986) himself. In the meantime the cointegration literature inaugurated by Granger (1981) saw the VAR transformed into the vector error correction model (VECM), and a further proposal is to place identifying restrictions drawn from economic theory on the cointegrating relationships, leaving

* Correspondence to: Kenneth F. Wallis, Department of Economics, University of Warwick, Coventry CV47AL, UK. E-mail: k.f.wallis@warwick.ac.uk 
the short-run dynamic and stochastic specification unrestricted. This approach is called 'longrun structural modelling' by Pesaran and Shin (2002), and it is applied in the construction of a small quarterly model of the UK economy by Garratt, Lee, Pesaran and Shin (2000, 2003; henceforth GLPS).

The objective of this article is to compare and contrast these two styles of empirical macroeconometric modelling, with reference to two models of the UK economy. Our representative of the SVAR style of modelling is the GLPS model noted above, and the SEM style of modelling is represented by the COMPACT model (Wren-Lewis et al., 1996; Darby et al., 1999).

Comparative studies of macroeconometric models have a literature extending back to the 1950s. Much of this literature is in the form of reports on model comparison conferences, comprising presentation of the results of model exercises carried out by the model proprietors, perhaps with commentary by independent economists. Less common is the model comparison project carried out by an independent third party who is granted full access to the models, their software and databases. Uniquely, the ESRC Macroeconomic Modelling Bureau (1983-99), directed by the second author, was of this form. The Bureau's research programme included regular comparative studies of models of the UK economy carried out entirely in-house, with the final article in the sequence (Church et al., 2000) also including a review of the research methods it developed and its experience with their use. Hands-on access to the models in particular allows the relevance of detailed structural features to notable differences in simulation results to be readily assessed. The present study enjoys the same access to the two models under consideration and takes the same approach to comparative research. It nevertheless provides an extension of previous research, since the two models exemplify different styles of modelling.

An important precursor is the 'Shocking stories' article by Levtchenkova et al. (1998). These authors bring together the cointegration literature and the empirical macroeconomics literature on the effects of shocks, and study the way in which information is brought to bear upon (stories are told about) impulse responses with respect to permanent and transitory shocks. We adopt their 'reverse engineering' procedure to infer long-run relations of COMPACT comparable to the cointegrating relations of GLPS. ${ }^{1}$

The article proceeds as follows. Section 2 briefly reviews the different dynamic systems under consideration, the different styles of impulse response analysis that they each employ, and the permanent-transitory distinctions that arise once variables are allowed to be integrated. The appraisal includes the generalized impulse response analysis proposed by Koop et al. (1996) and Pesaran and Shin (1998), since this approach is used by GLPS (2000) in reporting the dynamic properties of their model. Section 3 turns to the two models under consideration. Their key features, namely the economics behind the models and some relevant technical characteristics, are each described in turn. Various comparative questions are then considered, relating to their size, treatment of exogeneity and simulation design. Section 4 presents the results of model comparisons in two specific dimensions, namely the different impulse responses to the shocks considered by GLPS (2000, 2003), which we also implement on COMPACT, and the models' cointegration properties, explicit or implicit. Section 5 concludes.

\footnotetext{
${ }^{1}$ Their illustration compares the small cointegrated VAR model of King et al. (1991) (KPSW) with the more theoretically based, global-economy MSG2 model (see McKibbin and Sachs, 1991). 


\section{DYNAMIC SYSTEMS: REPRESENTATIONS AND PROPERTIES}

\subsection{Simultaneous Equation Models}

The dynamic linear SEM relating a vector of endogenous variables $y_{t}$ to exogenous variables $x_{t}$ with errors $u_{t}$ is written in structural form as

$$
B(\mathrm{~L}) y_{t}=G(\mathrm{~L}) x_{t}+u_{t}
$$

where $B(\mathrm{~L})$ and $G(\mathrm{~L})$ are matrix polynomials in the lag operator L. The leading coefficient matrix $B_{0}$ is subject to some normalization rule and allows contemporaneous interactions among endogenous variables. These are removed in the reduced form, which expresses each endogenous variable as a function of predetermined variables, as follows:

$$
y_{t}=B_{0}^{-1}\left\{B_{1} y_{t-1}+\cdots+B_{p} y_{t-p}+G(\mathrm{~L}) x_{t}\right\}+B_{0}^{-1} u_{t}
$$

with the convention that the autoregressive matrix polynomial is defined as

$$
B(\mathrm{~L})=B_{0}-B_{1} \mathrm{~L}-\cdots-B_{p} \mathrm{~L}^{p}
$$

Under an appropriate stability condition on $B(\mathrm{~L})$, the final form is given as

$$
y_{t}=B(\mathrm{~L})^{-1} G(\mathrm{~L}) x_{t}+B(\mathrm{~L})^{-1} u_{t}
$$

Here each endogenous variable is expressed as an infinite distributed lag of the exogenous variables, together with an error term comprising moving averages of the structural errors.

The coefficients in the expansion of $B(\mathrm{~L})^{-1} G(\mathrm{~L})$ are the dynamic multipliers or impulse responses, each column describing the effects on the endogenous variables over time of a unit shock to the corresponding exogenous variable. Cumulating these gives the long-run multipliers $B(1)^{-1} G(1)$, describing the steady-state responses to a unit step change or permanent shock in an exogenous variable. Similar impulse responses to direct perturbations to endogenous variables are given by the second term on the right-hand side of (3); SEMs are often programmed to allow such residual adjustments/intercept adjustments/add factors to elements of $u_{t}$ in practical forecasting exercises. A further practical note is that SEMs typically comprise mixtures of linear and loglinear equations and possibly include more complex forms such as the CES function, together with variables defined as products or ratios of other variables; this is true of the COMPACT model. Such non-linear systems are solved by numerical methods, and the dynamic responses described above are calculated as the difference between two solutions of a model, one a base run or control solution and the second a perturbed solution in which the relevant shock is imposed. The study of steady-state or long-run implications then requires a sufficiently long simulation base.

\subsection{Vector Autoregressions}

The VAR system is written

$$
A(\mathrm{~L}) z_{t}=e_{t}
$$

where the matrix polynomial $A(\mathrm{~L})$ has degree $k$ and leading matrix equal to the identity matrix, reflecting the reduced-form nature of the system. Once the $n$ variables in the vector $z_{t}$ have been selected, with reference to the problem at hand, there is no prior classification as endogenous or 
exogenous; all are treated equally as variables of interest to be modelled. Impulse responses are calculated from the vector moving average representation

$$
z_{t}=A(\mathrm{~L})^{-1} e_{t}=C(\mathrm{~L}) e_{t}
$$

where the leading matrix in $C(\mathrm{~L})$ is again the identity matrix. The elements of $e_{t}$ are correlated, that is, $E\left(e_{t} e_{t}^{\prime}\right)=\Omega$ is not diagonal, and Sims (1980) argued that it is useful to transform them to orthogonal form to be able to see the 'distinct patterns of movement' of the system. The triangular factorization $\Omega=T \Sigma T^{\prime}$, where $T$ is lower triangular with unit diagonal and $\Sigma$ is diagonal, gives the transformation $e_{t}=T \varepsilon_{t}$ such that $E\left(\varepsilon_{t} \varepsilon_{t}^{\prime}\right)=\Sigma$. The orthogonalized impulse responses $C(\mathrm{~L}) T$ then describe the consequences for $z_{t+s}, s=0,1, \ldots$, of unit shocks to the individual, mutually uncorrelated elements of $\varepsilon_{t}$. For the last element these are the same as the original impulse responses, since the last column of $T$ is $(0, \ldots, 0,1)^{\prime}$; for all other elements the shock has an instantaneous impact, not only on the corresponding $z$-variable, as in the original system, but also on all variables placed lower in the $z$-vector. The orthogonalized impulse responses thus depend on the ordering of the variables in the VAR. Often a further scaling of these impulse responses is reported by considering the diagonal matrix $\Sigma^{1 / 2}$ of the standard deviations of $\varepsilon_{t}$. Defining $S=T \Sigma^{1 / 2}$ gives the Cholesky decomposition $\Omega=S S^{\prime}$ and associated transformation $e_{t}=S \varepsilon_{t}^{*}$, and impulse responses to unit shocks to $\varepsilon_{t}^{*}$ are then reported. These are $C(\mathrm{~L}) T \Sigma^{1 / 2}$, and describe the dynamic consequences for the $z$-variables of a shock of one standard deviation in the orthogonalized residuals. It is not clear how interpretability is improved by scaling in inverse proportion to the goodness of fit of the equations of the VAR.

Writing the orthogonalized VAR as

$$
T^{-1} A(\mathrm{~L}) z_{t}=\varepsilon_{t}
$$

gives the appearance of the Wold causal chain, with contemporaneous coefficient matrix that is lower triangular with unit diagonal, and uncorrelated disturbances. This arises from the orthogonalization procedure rather than the imposition of prior restrictions from relevant economic theory. The recognition that structural analysis in VAR models requires such prior restrictions led to the development of SVAR models, as noted in the Introduction. The shocks are often given 'structural' names, such as supply, money demand, technology and so forth. Taking these to be the disturbance terms $u_{t}$ of a closed version of the SEM (1), (2), with covariance matrix $\Sigma$, attention usually focuses on the relation

$$
B_{0} \Omega B_{0}^{\prime}=\Sigma
$$

and seeks restrictions that identify $B_{0}$ and $\Sigma$ given the reduced form/VAR covariances $\Omega$. This approach eschews restrictions on the short-run dynamics, whereas in some applications restrictions on the long-run responses are used. It is common in the SVAR literature to assume $\Sigma$ diagonal, but this is not done in the SEM literature, and whether it is a reasonable restriction on an SVAR has been questioned, in the beginning by Bernanke (1986, pp. 51-55) himself and Shiller in discussion of Blanchard and Watson (1986), and in more recent reviews such as Pesaran and Smith (1998).

Generalized impulse response analysis (Koop et al., 1996; Pesaran and Shin, 1998; for a precursor see also Evans and Wells, 1983) is an alternative to orthogonalization, whether this is the result of prior restrictions or simple renormalization. Rather than attempting to describe responses to specified shocks, generalized impulse responses (GIRs) describe the effect of 'realistic' shocks, meaning shocks of the type that are typically or at least historically observed, as 
described by the sample estimate of the covariance matrix $\Omega$. If this is not diagonal, a shock to one error is associated historically with changes in the other errors. The GIRs, defined as conditional expectations given the estimated system, describe its dynamic responses to the resulting composite or generalized impulse. They are given as $C(\mathrm{~L}) \Omega^{\dagger}$, where $\Omega^{\dagger}$ denotes the matrix obtained from $\Omega$ by dividing the elements of each column by its diagonal element, since $E\left(e_{t} \mid e_{j t}=1\right)=\left(\omega_{1 j} / \omega_{j j}, \omega_{2 j} / \omega_{j j}, \ldots, \omega_{n j} / \omega_{j j}\right)^{\prime}$. The GIRs are invariant to the ordering of the variables in the VAR, and coincide with the orthogonalized impulse responses for shocks to the first variable in the VAR, since when $j=1$ the above column vector coincides with the first column of the matrix $T$ defined above.

\subsection{Cointegration and VECMs}

The VAR system (4) can be rearranged as

$$
A^{*}(\mathrm{~L}) \Delta z_{t}=-\Pi z_{t-1}+e_{t}
$$

where $\Pi=A(1)$ and the degree of $A^{*}(\mathrm{~L})$ is $k-1$. If the elements of $z_{t}$ are $I(1)$ and cointegrated with rank $(\Pi)=r, 0<r<n$, then $\Pi=\alpha \beta^{\prime}$ where $\alpha$ and $\beta$ are $n \times r$ matrices of rank $r$, giving the VECM representation

$$
A^{*}(\mathrm{~L}) \Delta z_{t}=-\alpha \beta^{\prime} z_{t-1}+e_{t}
$$

Exact identification of $\beta$ requires $r$ restrictions on each of the $r$ cointegrating vectors (columns of $\beta$ ): typically one is a normalization restriction. In the Wold representation of the differencestationary variables

$$
\Delta z_{t}=D(\mathrm{~L}) e_{t}
$$

the matrix $D(1)$ of rank $n-r$ is given in Johansen's (1991) presentation of the Granger representation theorem as

$$
D(1)=\beta_{\perp}\left[\alpha_{\perp}^{\prime} A^{*}(1) \beta_{\perp}\right]^{-1} \alpha_{\perp}^{\prime}
$$

where the orthogonal complements $\alpha_{\perp}$ and $\beta_{\perp}$ are $n \times(n-r)$ matrices of rank $n-r$ such that $\alpha^{\prime} \alpha_{\perp}=0$ and $\beta^{\prime} \beta_{\perp}=0$.

Various permanent-transitory decompositions follow from this representation. Stock and Watson (1988) show that, with $r$ stationary linear combinations $\beta^{\prime} z_{t}$, the $I(1)$ characteristics of $z_{t}$ are given by $n-r$ 'common trends' $\beta_{\perp}^{\prime} z_{t}$. The shocks that drive the common stochastic trends are the shocks $\alpha_{\perp}^{\prime} e_{t}$, called permanent shocks, leaving $r$ transitory shocks: since $\beta^{\prime} D(1)=0$, shocks to the cointegrating vectors have no permanent effects. Writing (8) as

$$
\Delta z_{t}=D(\mathrm{~L}) H^{-1} H e_{t}
$$

Levtchenkova et al. (1998) define a basic permanent-transitory decomposition as $H e_{t}$, with the first $n-r$ elements permanent and the last $r$ elements transitory, that is, $D(1) H^{-1}$ has its last $r$ columns equal to zero. Then $H$ has the form

$$
H=\left[\begin{array}{c}
\alpha_{\perp}^{\prime} \\
\rho^{\prime}
\end{array}\right]
$$

for any $n \times r$ matrix $\rho$ such that $H$ is invertible, and Levtchenkova et al. discuss various possible choices of $\rho$. 
Despite identification of the cointegrating vectors by restrictions on $\beta$, permanent-transitory decompositions require further structural identifying restrictions, or stories. Given $\beta$ and an initial choice of $\beta_{\perp}$, note that $\beta^{\prime} \beta_{\perp} P=0$ for any nonsingular $(n-r) \times(n-r)$ matrix $P$. If $n-r>1$, then identification of individual common trends $\beta_{\perp}^{\prime} z_{t}$ requires restrictions on $\beta_{\perp}$ that make transformations $P^{\prime} \beta_{\perp}^{\prime} y_{t}$ inadmissible, whereas if $n-r=1$, only a normalization restriction is required, as in KPSW's three-variable model. Likewise, identifying individual permanent shocks requires further restrictions: Fisher et al. (2000), for example, provide an alternative identification of permanent shocks to that assumed by KPSW for their six-variable model. Finally, given an estimate of $D(1)$ of rank $n-r$ by appropriately shocking a model, its implied cointegrating vectors can be obtained by prescribing $r^{2}$ (just-identifying) elements of $\beta$ and solving $\beta^{\prime} D(1)=0$ for the remainder. Levtchenkova et al. use such 'reverse engineering' to back out the cointegrating vectors underlying the MSG2 model for comparison with those of the KPSW six-variable model, and this procedure is used in Section 4 below.

\subsection{Partial and Conditional VECMs}

The practice of testing for weak exogeneity in cointegrated VAR models and imposing it when not rejected leads to partial systems with some similarity to the SEM. It is convenient to rewrite the VECM representation (7) as

$$
\Delta z_{t}=-\alpha \beta^{\prime} z_{t-1}+\sum_{i=1}^{k-1} \Gamma_{i} \Delta z_{t-i}+e_{t}
$$

and introduce conformable partitionings of relevant vectors and matrices as

$$
z_{t}=\left[\begin{array}{l}
y_{t} \\
x_{t}
\end{array}\right], \alpha=\left[\begin{array}{l}
\alpha_{y} \\
\alpha_{x}
\end{array}\right], \Gamma_{i}=\left[\begin{array}{l}
\Gamma_{y i} \\
\Gamma_{x i}
\end{array}\right], e_{t}=\left[\begin{array}{l}
e_{y t} \\
e_{x t}
\end{array}\right], \Omega=\left[\begin{array}{ll}
\Omega_{y y} & \Omega_{y x} \\
\Omega_{x y} & \Omega_{x x}
\end{array}\right]
$$

If $\alpha_{x}=0$ then $x_{t}$ is weakly exogenous and valid inference can proceed in the conditional (or partial) model of $y_{t}$ given $x_{t}$ and the past, namely

$$
\Delta y_{t}=\Lambda \Delta x_{t}-\alpha_{y} \beta^{\prime} z_{t-1}+\sum_{i=1}^{k-1} \tilde{\Gamma}_{y i} \Delta z_{t-i}+\tilde{e}_{y t}
$$

where $\Lambda=\Omega_{y x} \Omega_{x x}^{-1}, \tilde{\Gamma}_{y i}=\Gamma_{y i}-\Lambda \Gamma_{x i}$ and $\tilde{e}_{y t}=e_{y t}-\Lambda e_{x t}$. See Johansen (1995, ch.8), also Pesaran et al. (2000); the GLPS model is of this form.

The conditional VECM remains a reduced-form model in the sense of Section 2.1, with no contemporaneous relations among the elements of $y_{t}$. The requirement of full-system estimation for testing weak exogeneity, together with limitations on the length of the available time series, implies that these systems contain rather fewer variables than SEMs. In SEMs exogeneity is commonly assumed a priori, and such variables are not modelled. If, less commonly, exogeneity is tested, this is done in the context of individual estimated equations or small subsystems of the SEM, whose typical size precludes full-system estimation. 


\section{THE GLPS AND COMPACT MODELS OF THE UK ECONOMY}

\subsection{The Long-Run Structural VAR Model}

The GLPS model incorporates long-run structural relationships suggested by economic theory as the cointegrating relations of a VECM. The UK economy is a small open economy, subject to economic developments in the rest of the world, hence in the VAR approach both domestic and foreign variables are modelled. Data limitations constrain the number of variables to be included; in the first version of the model (GLPS, 2000) these comprise five basic domestic variables and four foreign variables. The variables are domestic and foreign real per capita outputs $\left(y, y^{*}\right)$, producer prices $\left(p, p^{*}\right)$ and nominal interest rates $\left(r, r^{*}\right)$, the nominal effective exchange rate $(e)$, the price of oil $\left(p^{o}\right)$ and the domestic real per capita stock of money $(h)$, all modelled in logarithms.

The underlying economic theory delivers five long-run relations or equilibrium conditions among these variables, based on production, arbitrage, solvency and portfolio balance conditions, together with stock-flow and accounting identities. First is a purchasing power parity relation, based on international goods market arbitrage, modified by the effect of oil prices (cf. Chaudhuri and Daniel, 1998). Next, a nominal interest rate parity relation, based on arbitrage between domestic and foreign bonds. Then an 'output gap' relation derived from the neoclassical growth model, assuming common technological progress in production at home and overseas. Last are trade balance and real money balance relations, based on long-run solvency conditions and assumptions about the determinants of the demand for domestic and foreign assets.

Many more variables than these nine appear in the theoretical framework, but are solved out. Expectations of several variables also appear, but are replaced by their actual values; it is assumed that expectational errors are stationary processes subsumed into the disturbance terms. The economic theory says nothing about the statistical characteristics of the variables, but once it is assumed that they are difference-stationary these equilibrium relations become candidate cointegrating relations in the VECM representation. It is not a necessary condition in the VECM approach that long-run relations include only integrated variables, nevertheless the authors choose to require this.

The GLPS (2000) model is estimated from quarterly data over the period 1965q1-1995q4. The number of variables is reduced to eight by measuring domestic and foreign price variables relative to the oil price, and all eight are treated as I(1), since this null hypothesis cannot be rejected in univariate pretesting. The cointegration rank is estimated as five, in agreement with the number of long-run relations of the theoretical model. With the variables ordered

$$
\left(p-p^{o}, e, r, r^{*}, y, y^{*}, h-y, p^{*}-p^{o}\right)
$$

the estimate of the $8 \times 5$ matrix $\beta$ is

$$
\left[\begin{array}{ccccc}
1 & 0 & 0 & 1 & 0 \\
-1 & 0 & 0 & -1 & 0 \\
0 & 1 & 0 & -11.55 & 20.32 \\
0 & -1 & 0 & 0 & 0 \\
0 & 0 & 1 & 1.52 & 0 \\
0 & 0 & -1 & 0 & 0 \\
0 & 0 & 0 & 0 & 1 \\
-0.91 & 0 & 0 & -1 & 0
\end{array}\right]
$$


the last two cointegrating relations also containing time trends. This matrix is highly overidentified, and the overidentifying restrictions are not rejected at the $10 \%$ level once bootstrapped rather than asymptotic critical values are compared to the likelihood ratio statistic. The foreign price relative to oil is then treated as weakly exogenous, giving a seven-equation conditional VECM for the remaining variables, of the form (10). It has a single lag in all variables, that is, $k=2$.

The dynamics of the seven-equation system can be summarized by the $7 \times 7$ matrix $C(\mathrm{~L})$ of impulse responses defined in equation (5), together with the responses of the endogenous variables to the weakly exogenous $\left(p^{*}-p^{o}\right)$. These are presented diagrammatically in Figure 1 . The innovations are $1 \%$ (one annual percentage point for the interest rates), except for the foreign price relative to oil, which is scaled to give a long-run response of $1 \%$ deviation from base. The innovations are applied in period 0 , and responses are shown up to and including quarter 50, as in the GIR illustrations of GLPS (2000). Each column represents the responses to a shock to the diagonal element; off-diagonal impact effects for the first seven columns are equal to zero. The exogenous variable enters the VAR contemporaneously, although its impact effects, and dynamic effects more generally, are small for all but the domestic relative price variable. A temporary shock has a permanent effect on an $I(1)$ variable, and convergence to the long-run response is in most cases relatively quick. These are given alternatively as $C_{\infty}$ or $D(1)$ in representations (5) and (8) respectively, and can be calculated directly from expression (9) to check how close dynamic responses are to their steady-state values. Since $\beta^{\prime} D(1)=0$, the long-run responses of $r$ and $r^{*}$ are equal in each column, as are those of $y$ and $y^{*}$.

The second version of the model (GLPS, 2003) extends the estimation period to $1999 \mathrm{q} 4$ and adds the UK Retail Prices Index $(\tilde{p})$ to the list of variables. Now the price variables treated as $I(1)$ are the relative producer price levels $p-p^{*}$, the RPI inflation rate $\Delta \tilde{p}$ and the oil price $p^{o}$. In the event the last variable does not appear in the cointegrating relations, so the purchasing power parity relation reverts to its simple form, with no oil price effects. The cointegrating relations remain five in number, the only other change being the replacement of the trade balance relation by a

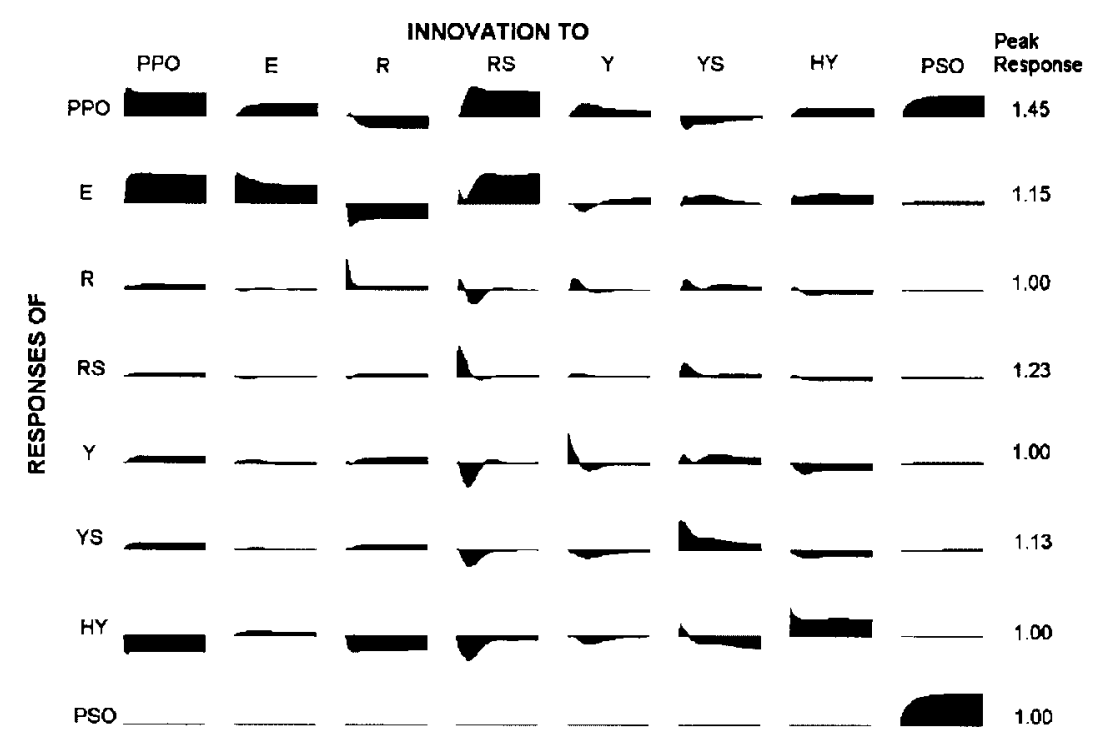

Figure 1. Impulse responses of the GLPS (2000) model 
Fisher interest parity relation: the ex post real interest rate is stationary. Again using bootstrapped critical values, the 23 overidentifying restrictions are not rejected at the $5 \%$ level $(L R=71.49)$. The oil price is treated as weakly exogenous, and the conditional VECM form of the model now has eight equations. The two versions of the model are used in turn in Section 4 below.

\subsection{The COMPACT Model}

The COMPACT model (Wren-Lewis et al., 1996; Darby et al., 1999) is a SEM, designed to translate modern macroeconomic theory into an econometric model that is both consistent with past evidence and capable of producing quantitative policy analysis. Its name reflects its relatively small size among UK SEMs, with fewer than 20 estimated behavioural equations, together with other estimated equations that set the weights in a disaggregated price system or estimate growth rates in simple projections, for oil output and population, for example. It is estimated using modern time-series econometric techniques at the single-equation or small subsystem level, with error correction specifications where relevant, although interest rates and inflation are not treated as integrated variables, unlike GLPS. The model can be described as New Keynesian, combining traditional Keynesian nominal rigidities with forward-looking behaviour in wage and price setting. In the short run output depends on effective demand, the main components of which are separately modelled. In particular, the consumption function is consistent with a forwardlooking Blanchard-Yaari life cycle model, except that some consumers are credit constrained and spend all their available income.

The model's medium-term properties are strongly influenced by its vintage or 'putty-clay' production technology in which there are no factor substitution possibilities once a new vintage of capital investment is installed, and so expected future factor prices are important in the investment decision. A change in technical progress, for example, is only gradually embodied in the capital stock as a result of its vintage structure. In this respect the model is unique among current UK SEMs. In the long run, however, the model behaves as if the ex post (Cobb-Douglas) production technology were putty-putty.

The long-run properties of COMPACT are close to those of an open-economy version of the standard neoclassical growth model: it is neutral, but not super-neutral, since nominal interest payments are taxed. Although these theoretical properties are well understood, there is no formal description of the model's long run, hence a long-run solution can only be observed numerically, by simulation methods. Forward expectations variables are treated as rational or model-consistent expectations, and in solving non-linear rational expectations models it is important to ensure that the terminal date for the simulation is sufficiently far into the future that the simulation is unaffected by the choice of terminal date. These considerations lead to the use of a solution period of 280 quarters in the model's normal mode of operation. The normal operating environment also includes closure rules/reaction functions for fiscal and monetary policy.

\subsection{Comparative Issues}

The GLPS and COMPACT models clearly differ in size, the latter containing approximately 10 times as many variables as the former. Comparisons of what the models have to say about the behaviour of key variables can only consider variables that are common to both, hence the greater detail that COMPACT provides must be left on one side. All but one of the variables of the 
GLPS model have counterparts in COMPACT, sometimes with minor variation in the measure used, and this defines the range of our comparisons. The GLPS variable that does not appear in COMPACT is money. It is obviously a component of the net financial assets variables that appear in COMPACT, but it is not separated out, and the model has no money demand function, for example. Thus our comparison of the two models' long-run implications focuses on four of the GLPS cointegrating relationships and neglects the money market equilibrium condition.

The original VAR style of modelling is noticeably distinct from the SEM in abandoning the classification of variables as endogenous or exogenous. In the closed economy context of much of the early empirical VAR analysis - the US economy, that is - this meant treating policy variables as endogenous, and SEMs have tended to follow suit, now containing policy reaction functions in place of their previous treatment of policy instruments as exogenous variables. In an open economy context, however, the distinction remains, as in our present examples. The GLPS model treats the overseas economy in the same way as the domestic economy, whereas COMPACT neglects the effect of the UK economy on the rest of the world, and treats 'world' variables as exogenous and mostly unmodelled. The world investment and output variables are related to the world trade variable to ensure mutual consistency of their growth paths, but this subsystem is causally prior to the rest of the model. There are no interactions in COMPACT among the three corresponding world variables treated as endogenous by GLPS, and in the simulation base they are projected forward at constant values $\left(r^{*}\right)$ or constant growth rates $\left(y^{*}, p^{*}\right)$. An alternative scenario in which they behave in a coherent manner would need careful design by the model user before being input as exogenous variable trajectories to the COMPACT solution. ${ }^{2}$

\section{COMPARATIVE DYNAMICS}

\subsection{Impulse Responses to a Foreign Output Shock}

We use the shock to the foreign output equation of GLPS (2000, Figs 5.2-5.4) first to compare the different styles of impulse response analysis, and then to compare the two models. Their generalized impulse responses relate to a composite shock to all variables of the model, as given by the correlations between the residuals of the foreign output equation and the other equations. We first compare these to the conventional impulse responses (IRs) of the same model, in which only the foreign output variable is shocked; the latter appear in the sixth column of Figure 1. As noted above, the traditional approach of shocking a single variable without reference to possible

\footnotetext{
${ }^{2}$ For coherent modelling of the external economic environment a multicountry model might be employed. Several SEMstyle global models are in current use, with recent comparative analysis provided by Mitchell et al. (1998) and Wallis (2004), for example. In such models several countries or groups of countries are each modelled at a level of detail comparable to that of a national-economy SEM, and their trade and financial interrelationships are made explicit, so that various spillover questions and responses to asymmetric shocks can be analysed. Also comparable to a national-economy SEM is the treatment of 'foreign' variables as exogenous, but these in turn are modelled in their own-economy blocks. Consistent global modelling then requires that trade balances and net foreign asset positions sum to zero at all times. Pesaran et al. (2004) implement a SVAR-style approach to global modelling in their global VAR (GVAR) model. Each country or regional block is a conditional VECM of similar dimension to the GLPS UK model. Unlike GLPS, however, the foreign variables in each separately estimated country submodel are treated as weakly exogenous, following statistical testing. As in the SEM-style models, global consistency constraints are then imposed in solving for all the variables in the global economy simultaneously. Like the UK models in our present study, the SEM-style and SVAR-style global models differ substantially in size. Within the SVAR style of modelling, however, GLPS and GVAR represent different approaches to modelling the UK economy's external environment.
} 
residual correlations is equivalent to placing the variable in the last position when using Cholesky orthogonalization.

The shocks are designed to give an increase in foreign output of $1 \%$ in the long run. To calibrate the required initial shocks and help interpret the long-run responses we first calculate the matrix $D(1)$ of long-run multipliers via equation (9), with the following results:

$\left[\begin{array}{ccccccccc}1.089 & 0.664 & -2.306 & 4.645 & 0.247 & -0.058 & 0.358 & -0.702 \\ 1.089 & 0.664 & -2.306 & 4.645 & 0.247 & -0.058 & 0.358 & -5.281 \\ 0.028 & -0.005 & 0.095 & 0.016 & -0.001 & 0.022 & -0.030 & -0.153 \\ 0.028 & -0.005 & 0.095 & 0.016 & -0.001 & 0.022 & -0.030 & -0.153 \\ 0.211 & -0.035 & 0.722 & 0.125 & -0.007 & 0.166 & -0.229 & -0.880 \\ 0.211 & -0.035 & 0.722 & 0.125 & -0.007 & 0.166 & -0.229 & -0.880 \\ -0.565 & 0.093 & -1.937 & -0.334 & 0.018 & -0.446 & 0.614 & 3.116 \\ 0 & 0 & 0 & 0 & 0 & 0 & 0 & 5.008\end{array}\right] \begin{gathered}p^{o} \\ r^{*} \\ y^{*}-y \\ p^{*}-p^{o}\end{gathered}$

The variables are ordered as in Section 3.1, repeated in the right-hand column for convenience. Since there are five cointegrating relations among the eight variables, this matrix has rank 3 . The first two rows are equal except for the last element, which is the only non-zero element in the last row, whose first seven zeros reflect the treatment of $p^{*}-p^{o}$ as weakly exogenous in the VECM and so not affected by shocks to the other variables. The third and fourth rows are equal, the long-run effect of shocks on the cointegrating combination $r-r^{*}$ being zero, likewise $y-y^{*}$, the fifth and sixth rows. Finally rows 3, 5 and 7 are proportional to one another (though rounding may obscure this).

To achieve a long-run IR of $1 \%$ in foreign output an impulse of $0.166^{-1}=6 \%$ is required. To achieve the same long-run GIR of foreign output the required impulses to the seven variables depend on the long-run responses of foreign output to the individual shocks, as given by the sixth row of $D(1)$, and their correlations with the foreign output shock. In the event the combined shock's foreign output impulse is $2.5 \%$. The complete set of shocks that form the generalized impulse is

$$
\begin{array}{ccccccc}
p-p^{o} & e & r & r^{*} & y & y^{*} & h-y \\
-0.36 & -0.81 & 0.27 & 0.19 & 1.80 & 2.52 & -1.84
\end{array}
$$

and using these weights to construct a linear combination of the first seven columns of Figure 1 yields the GIRs. Since the long-run responses of the third through seventh variable to the different shocks are in the same proportion, it follows that the long-run IR equals the long-run GIR for each of these variables. This does not hold for the first two variables, since their responses to the various shocks differ from those that determine the weights in the combined shock that equates the long-run GIR and IR for foreign output. Nevertheless, the long-run IRs of these variables are equal to one another, and so are their long-run GIRs in this experiment, since the foreign price variable is not perturbed.

The alternative impulse responses for five variables are plotted in Figure 2. The profiles of the GIRs correspond to those in figs 5.2-5.4 of GLPS (2000), though the scale is slightly different; the time horizon of 50 quarters is the same. This is not quite long enough to demonstrate the convergence of IRs and GIRs in all the cases noted in the previous paragraph. Running the solution on shows that this is accomplished in $75-100$ quarters.

The GIRs show a non-zero initial impact in all variables, by design, and this combined shock brings foreign output to its long-run response much more quickly than the shock to this variable alone. The shock to $h-y$ makes approximately the same contribution to the $1 \%$ long-run response 

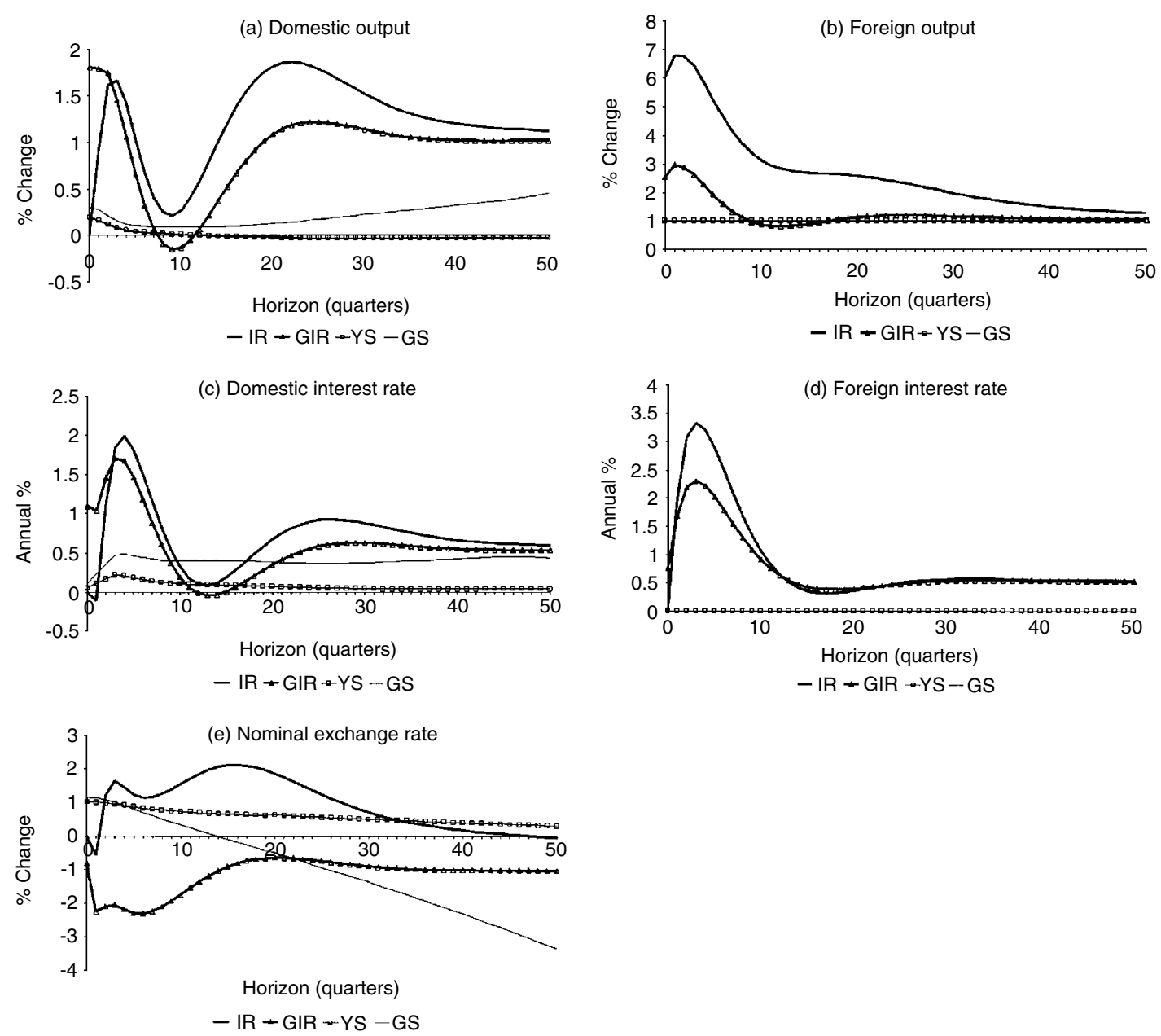

Figure 2. Impulse responses to a permanent $1 \%$ foreign output shock

of foreign output as the $y^{*}$ shock itself, and we note from the $(6,7)$ cell of Figure 1 that the foreign output response to $h-y$ reaches its long-run level relatively quickly. For other variables the IRs show greater fluctuations over the first $2-3$ years than the GIRs, thus averaging the IRs across the rows of Figure 1 to obtain the GIRs in general serves to smooth the intermediate fluctuations.

Similar combinations of IRs give the orthogonalized impulse responses, once an ordering of variables has been chosen and a corresponding triangular factorization or Cholesky decomposition of $\Omega$ undertaken. In a cointegrated VAR, where IRs do not converge to zero, this example illustrates that different combinations imply different long-run responses and hence that the choice of ordering is not innocuous, contrary to what is often asserted by proponents of orthogonalization, who perhaps have stationary or trend-stationary systems in mind.

Turning to model comparisons, we note the two impulse responses for COMPACT also plotted in Figure 2. The first, labelled YS, relates to a shock to the world output, investment and trade 
variables, which are constrained to move in step, but to no other exogenous variables. The domestic responses to this shock are small. The nominal exchange rate jumps on impact, then slowly declines to reach a steady-state level $0.21 \%$ below base. This is close to the long-run IR of the exchange rate in GLPS, which is $0.35 \%$ below base, but these experiments are not as comparable as they appear at first sight, as is discussed next.

To design a more comparable COMPACT experiment we consider the possible sources of a foreign output shock in the GLPS model. It contains no labour supply or fiscal policy considerations; rather, the evolution of per capita output is largely determined by technological progress. And given the small and open nature of the UK economy, it is assumed that domestic technological progress is determined by technological progress in the rest of the world in the long run: this is the theoretical foundation for the model's 'output gap' cointegrating relation. In this spirit we interpret a foreign output shock as a global technology shock, and to obtain an equivalent scenario we also adjust COMPACT's exogenous domestic technical progress variable. Since the modelled output variable is non-oil GDP, and the UK output of oil is simply projected forward at a constant growth rate, for consistency we also adjust this growth path. The responses to this scenario are labelled GS in Figure 2. The solution period for COMPACT is 280 quarters, as noted above, and the rate of convergence is slow, so that after the 50 quarters shown in the plots considerable adjustment still remains to be accomplished. The results for the full period show that the eventual steady-state increase in domestic output is $1 \%$, as in GLPS. The domestic interest rate returns to base, and as the foreign interest rate has not been perturbed and the uncovered interest parity condition holds, the exchange rate stabilizes, at a level $3.4 \%$ below base. Among other variables employment returns to base, so that the increase in average labour productivity matches the increase in technical progress and the natural rate of unemployment is unaffected, although there are transient unemployment costs during the adjustment process.

The relatively sluggish response of domestic output in COMPACT to improved technology is due to its vintage capital production system, in which it takes approximately 20 years before all the capital stock in use benefits from the improvement. The GLPS model does not explicitly model the investment process and the influence of technical progress upon it, but simply captures the 'stylized facts' of the dynamic interrelationships of domestic and foreign output and the remaining variables of the system. To the extent that the technical progress story behind the foreign output shock in the GLPS model is treated as comparable to an intervention on COMPACT's rate of labour-augmenting technical progress, the VAR evidence suggests that the domestic output response in COMPACT is unrealistically slow. Although this is the only current UK SEM that incorporates a vintage capital model of production, as noted above, Gilchrist and Williams (2000) argue for its empirical relevance in the USA. Their DSGE model with putty-clay technology shows much quicker output responses to technology shocks than COMPACT, suggesting that dynamic specification choices within the vintage framework, rather than the vintage framework itself, may be the cause of COMPACT's sluggishness.

\subsection{Effects of an Oil Price Shock}

Our second simulation reproduces the oil price experiment of GLPS (2003). This uses the second version of the model, in which the oil price variable appears in its own right, as an exogenous variable in the model's short-run dynamics. The shock is an increase of $16.485 \%$, equal to one standard error of the projection equation for this variable which is estimated for use in other 
model exercises. It is also implemented on COMPACT, which likewise treats the oil price as an exogenous variable.

Impulse responses for the two variables of major interest are presented in Figure 3. The GLPS results correspond to those shown in the relevant panels of GLPS (2003)'s Fig. 2, where 95\% confidence error bands are also shown. We note that, in contrast to our deterministic solutions, they show the mean values of the empirical distributions of the impulse responses generated from the bootstrap procedure used to calculate the standard error bands; however, there are no perceptible differences between the two sets of results. The GLPS confidence intervals cover zero for all but a few early periods for a few variables, although their lack of reliability as indicators of the precision of the estimates beyond the first 1 or 2 years is noted.

The domestic output response provides the major contrast between the two models. Aside from questions of its statistical significance, this is negative in GLPS, approximately $0.24 \%$ below base after 2.5 years, with foreign output responding more slowly than domestic output, but reaching the same long-run decline of $0.16 \%$. GLPS (2003) describe the negative sign of the effect on output as 'expected', although there is no story provided and the oil price does not appear in the model's theoretical development. On the other hand the domestic output response is strongly positive in COMPACT, $0.5 \%$ above base in the long run. Equivalent calculations of error bands for this model are not feasible, but regarding the GLPS calculations as a relevant data summary, we note that the COMPACT response lies above a 95\% interval around zero after 30 quarters, and outside the GLPS interval estimate somewhat earlier. In the COMPACT solution the UK is a net oil exporter, although oil output contributes less than $4 \%$ of GDP at the start of the simulation
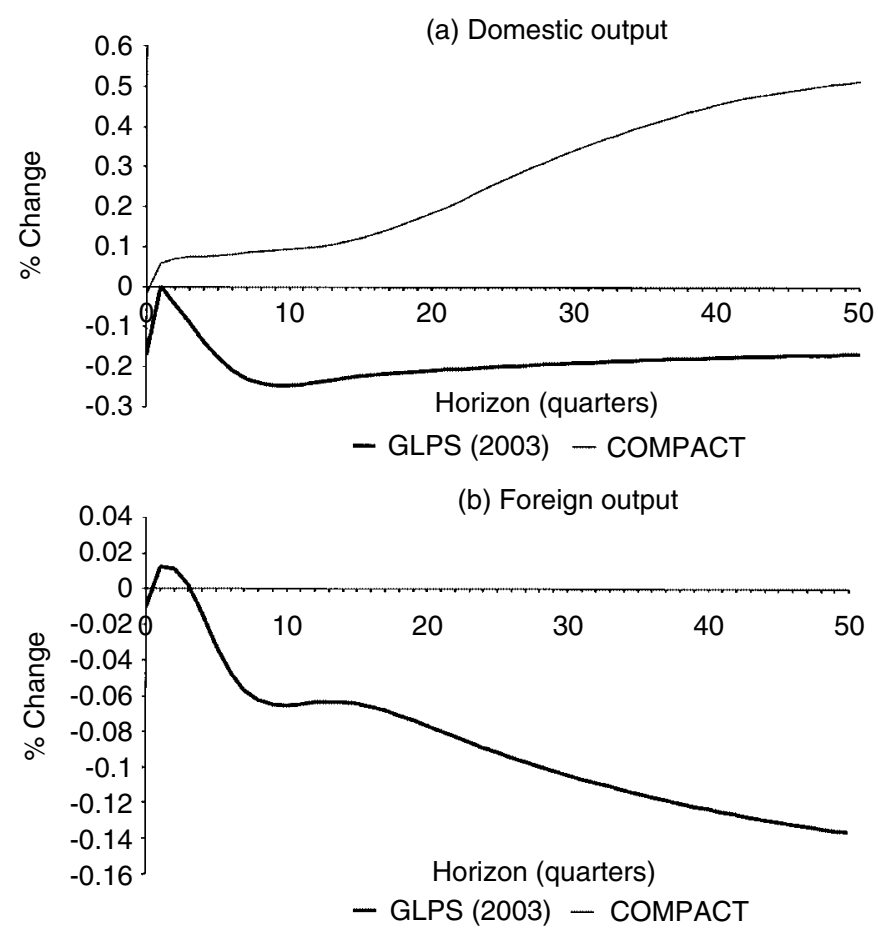

Figure 3. Impulse responses to a permanent $16.485 \%$ oil price shock 
base. The UK nevertheless receives a permanent income gain from a permanent increase in the oil price. This increase in income allows the economy to increase the capital stock, supporting permanently higher output. The rise in the oil price improves the current account, and balance is restored by increased import demand induced by the change in output.

The GLPS model does not provide comparable detail, but simply reflects the correlations between its endogenous variables and the oil price in a reduced-form manner. The behaviour of the price of oil over the sample period is dominated by four main shocks, namely the OPEC I and II rises of the 1970s, the sharp fall in 1985-6, and the rise associated with the Iraqi invasion of Kuwait in 1990. The first two were the more dramatic changes, each followed by recession. The subsequent consensus, however, is that each recession had more than this single cause. Monetarists point to the surge in monetary growth in 1972-3 which preceded the inflationary explosion and falling output of 1974-5, while other commodity prices than oil were also rising exceptionally quickly in 1973. The 1979 oil-price shock initiated a second recession across the OECD economies, although in the UK it started earlier than elsewhere and was of much greater severity, despite its near self-sufficiency in oil by that time. Subsequent analysis places greater weight on the restrictive monetary and fiscal policies of the June 1979 budget (Mrs Thatcher's first) and the unanticipated deterioration in competitiveness as factors explaining the shortfall in output. Disentangling these effects clearly requires more complete modelling of the domestic economy than is provided by the eight-variable GLPS model.

The modelling of the world economy in GLPS is an important distinguishing feature, as noted above, and this represents a potentially important transmission mechanism. With the world output measure dominated by oil-importing nations, its negative response to the oil price rise is to be expected. This is associated with a domestic output response of the same sign-and, in the long run, of the same magnitude - in the estimated model. The UK's move from oil importer to oil exporter occurred midway through the sample period, and the VECM estimates simply average these effects. If the GLPS model is re-estimated over a split sample, 1965q1-1979q4 and 1980q1-1999q4 respectively, but with unchanged cointegration relations, the long-run responses of domestic and foreign output are reduced from -0.16 in the earlier period to -0.01 in the later period. General sensitivity to oil-price movements has fallen in the last two decades.

The overall conclusion is that, while this experiment provides a good illustration of differences in the properties of the two models, neither model provides a complete answer to the substantive economic question it poses. The reduced-form GLPS model is not able to accommodate structural change of the kind induced by the exploitation of North Sea oil; the COMPACT model is not able to capture the effect of a world recession induced by a rise in the price of oil without further intervention by the model user, which we did not attempt.

\subsection{Long-Run Structural Relations}

To compare the long-run implications of COMPACT with the long-run structural relations of GLPS, estimated as cointegrating relations, we employ the reverse engineering procedure of Levtchenkova et al. (1998), discussed in Section 2.3. For this purpose we require an estimate of the long-run responses to permanent shocks for the variables of COMPACT that are comparable to those of GLPS, irrespective of whether or not COMPACT treats them as integrated variables. As noted above, a money variable does not appear in COMPACT, so it cannot feature in the comparison. In the GLPS cointegrating relations this variable appears only in its 'own' money market equilibrium 
condition, so ignoring this equation and focusing on the remaining four long-run relations causes no additional complication. For the present comparison we take the second version of the model (GLPS, 2003) which, like COMPACT, treats the oil price as exogenous. The four cointegrating relations under consideration are heavily overidentified, the only estimated coefficient in each relation being the constant term. As noted in the closing paragraph of Section 3.1, relative prices $p-p^{*}$ are defined as a single variable, and the four cointegrating combinations of the seven variables under consideration are $p-p^{*}-e, r-r^{*}, y-y^{*}$ and $r-\Delta \tilde{p}$.

These adjustments leave the number of permanent shocks at three, and we require three experiments that deliver a $7 \times 3$ matrix of long-run responses of rank 3; this corresponds to the nonzero columns of $D(1) H^{-1}$ in the basic permanent-transitory decomposition of Levtchenkova et al. (1998) discussed above. In principle any combination of the variables could be shocked permanently, however this needs to be done in a coherent manner. This is particularly important in a forward-looking model like COMPACT, where the long-run effects of exogenous shocks may have a strong influence on short-run behaviour. An unsustainable long-run debt position, for example, should result in a failure of the model solution. Some numerical procedures may be sufficiently robust to pretend that a solution exists in such cases, and it is important to be alert to this possibility.

First we take the global technology shock of Section 4.1, in which a long-run increase in exogenous foreign output is assumed to be the result of an increase in technological progress which occurs both at home and overseas. No other foreign variables are perturbed. After a protracted period of adjustment this produces the same long-run response in endogenous domestic output.

The second shock is a monetary policy shock, specifically a change in the inflation target in the monetary policy rule, as used in previous comparative research on UK models (Church et al., 1997, 2000). The inflation target is increased by $0.1 \%$, and the policy rule delivers a long-run increase of the same amount in domestic inflation and domestic interest rates, leaving the real interest rate unchanged. We assume that this is a global shift in monetary policy, and impose equivalent increases in exogenous foreign interest rates and inflation. Although the dynamic adjustment paths are not controlled, in the long run the real exchange rate is unaltered. The results are consistent with the theoretical proposition that changing the steadystate inflation rate leaves real variables unchanged in the long run. We note that this experiment is not consistent with the treatment of interest rates and inflation as I(1) variables by GLPS. In that context the target in the monetary policy experiment of GLPS (2003) is expressed as a desired constant reduction in the rate of inflation from that observed in the previous period; this does not correspond to the inflation targeting regime now prevalent in many OECD member countries.

To complete the matrix of long-run responses we return to a traditional shock-one-thing-at-atime simulation experiment, intended to elucidate reduced-form properties, but which may not represent a plausible scenario. We apply a permanent increase of $1 \%$ to the exogenous foreign price variable of COMPACT, but leave all other exogenous variables at their base-run values. On impact the nominal exchange rate jumps by a smaller amount $(0.83 \%)$, and is associated with falls in domestic prices and inflation and an increase in domestic output. The unwinding of these effects under an inflation-targeting policy rule that has no foreign counterpart leaves the domestic price level $0.41 \%$ lower in the long run. The price differential is matched by the nominal exchange rate, with the real exchange rate and all other endogenous variables returning to base by the end of the simulation. 
The long-run responses of the seven relevant variables in COMPACT in these three experiments are as follows:

\begin{tabular}{|c|c|c|c|}
\hline-3.30 & 0.55 & $-1.41]$ & $p-p^{*}$ \\
\hline 3.37 & 0.55 & -1.41 & $e$ \\
\hline 0 & 0.1 & 0 & $r$ \\
\hline 0 & 0.1 & 0 & $r^{*}$ \\
\hline 1 & 0 & 0 & $y$ \\
\hline 1 & 0 & 0 & $y^{*}$ \\
\hline 0 & 0.1 & 0 & $\Delta \tilde{p}$ \\
\hline
\end{tabular}

The reverse engineering procedure now seeks their orthogonal complement, such that $\beta^{\prime} D(1) H^{-1}=$ 0 , for comparison with the cointegrating combinations of GLPS. It is immediately clear that $r-r^{*}, y-y^{*}$ and $r-\Delta \tilde{p}$ appear here, as in GLPS, whereas a simple purchasing power parity (PPP) relation does not. Normalizing a fourth relation on $p-p^{*}$, however, and assuming nonzero coefficients on $e$ and $y$, yields $p-p^{*}-e+0.07 y$, which represents a small deviation from the PPP relation of GLPS (2003). We recall that the first version of the model (GLPS, 2000) also contains a small deviation from PPP: the simple relation is modified by the effect of oil prices, although that variable does not appear in the cointegrating relations of the second version of the model under consideration at this point.

Calculations analogous to those of Levtchenkova et al. $(1998$, fn. 15) show that adding this extra term $0.07 y$ to the PPP relation of GLPS (2003), while retaining the fifth cointegrating monetary equilibrium relation to ensure comparability, increases the $L R$ statistic from the value 71.49 noted above to 72.27 . Thus there is a small deterioration in goodness-of-fit, although the bootstrapped $5 \%$ critical value of the $L R$ statistic is 73.19 , hence this COMPACT steady-state relation, or any other observationally equivalent fourth relation, would be data-admissible in the VAR context. The theoretical structure of COMPACT does not assume that PPP holds in the long run. In the context of a small open economy, with the rest of the world exogenous, the real exchange rate in the long run equates the demand and supply of domestic output.

\section{CONCLUSION}

The two models of the UK economy studied in this article each aim, within their different styles of modelling, to provide a sounder foundation in modern macroeconomic theory than is customary in that style. Comparisons between them, however, emphasize and are in turn limited by particular features of each modelling style, rather than differences in their theoretical structures. Two features that strongly influence our analysis are the relative sizes of the models and their different approaches to exogeneity questions. These features are related to one another.

Comparisons of models of different sizes invariably have to adopt a 'lowest common denominator' approach, and neglect the wider range of issues that the larger model, in this case COMPACT, can address. On the other hand, its size precludes full-system estimation and testing. Variables relating to domestic policy and the rest of the world were traditionally treated as exogenous, unmodelled variables in national-economy SEMs. That policy variables should be treated as endogenous is now generally accepted by both SVAR and SEM schools; in the context of models of small open economies, however, differences remain in the treatment of variables describing the external economic environment. Modelling jointly with domestic variables in a VAR has advantages, indeed is required if weak exogeneity is to be tested prior to possible conditioning. But data limitations 
constrain the number of variables that can be considered, which in turn raises issues of omitted variable bias. If external variables are assumed to be individually exogenous, unmodelled variables, as is typical in the much larger SEM, then the design of global-economy scenarios in which such variables interact realistically requires additional information - a supplementary model, in effect-and there are obvious opportunities to combine information from the two approaches, as shown in the exercises presented above. In the SVAR approach, there are differences in the treatment of the external economic environment between the GLPS UK model and the UK block of the global VAR model of Pesaran et al. (2004); comparisons between them are awaited.

Two aspects of the dynamic properties of the models are studied in this article, namely impulse response analysis and cointegration analysis. Our experience with the former is that traditional shock-one-thing-at-a-time dynamic multiplier analysis remains an essential part of the toolkit. Even if the argument for generalized impulse response analysis - that this is how shocks were cross-correlated in the data-is accepted, understanding of the responses to a package of shocks requires knowledge of the individual component responses. Here, as elsewhere in economics, these partial derivatives are the key to understanding the behaviour of the system. Focusing on the steady-state or long-run implications does not evade the issue. In a cointegrated VAR impulse responses converge to zero only for the cointegrating combinations of variables, and the individual responses are the basic ingredients of the analysis of the response of any other combination of variables, whether constructed by orthogonalization, generalization, etc.

The first of our two impulse response experiments, a global technology shock, reveals differences in adjustment dynamics between the two models, whereas the oil price simulation brought to the fore a design difference. Whether the UK is a net oil importer or exporter has an important bearing on the nature and interpretation of the response to an oil price shock. The COMPACT model captures this structural change, with the simulation representing the position of a net oil exporter, which is appropriate for current policy analysis. The reduced-form GLPS model blurs the evidence across the structural break, and its small size limits the analysis of important historical episodes in which oil price movements played an important part, but only a part. Its size represents a more general limitation on the range of theoretical insights that can be obtained and the range of policy questions that can be addressed. On the other hand its system-wide estimation provides an efficient data summary that presents evidence in the first simulation against the sluggish dynamic behaviour of COMPACT.

Cointegration analysis and the error correction model are in widespread use in both small-scale and large-scale macroeconometric modelling, and their general principles are accepted by both SVAR and SEM modellers, as in our present examples. The lack of degrees of freedom leads the latter to use this approach in the specification of individual estimated equations, or small subgroups of related equations, within a larger system, whereas system-wide estimation is undertaken in the smaller SVAR systems, as noted above. Differences arise in statistical modelling, however, since the long-run or equilibrium position of COMPACT does not involve only integrated variables, whereas this restriction is required by GLPS, although it is not necessary in the VECM approach. Despite this our analysis finds much common ground in the long-run implications of the models: they share a nominal interest parity condition, an 'output gap' relation in relevant scenarios, and a Fisher interest parity condition, although COMPACT does not assume that PPP holds in the long run. GLPS (2003) acknowledge that their treatment of interest rates and inflation rates as integrated variables raises 'interesting issues concerning the use of economic theory and statistical evidence in macroeconometric modelling'; these also concern the nature of the policy experiments 
that can be implemented on their model, which are a subject of continuing research in the context of model comparisons.

\section{ACKNOWLEDGEMENTS}

The helpful advice of Tony Garratt and Simon Wren-Lewis on the installation and operation of the models, and the support of the Research School SOM, University of Groningen, are gratefully acknowledged. The article has benefitted from comments received following presentations of previous versions at the European Meeting of the Econometric Society, Venice, August 2002, the Tinbergenweek Conference at Erasmus University, Rotterdam, April 2003, and many seminars and workshops. Helpful comments were also received from this journal's editors and referees.

\section{REFERENCES}

Bernanke BS. 1986. Alternative explanations of the money-income correlation. Carnegie-Rochester Conference Series on Public Policy 25: 49-99.

Blanchard OJ, Watson MW. 1986. Are business cycles all alike? (with discussion). In The American Business Cycle, Gordon RJ (ed.). University of Chicago Press for NBER: Chicago; 123-179.

Chaudhuri K, Daniel BC. 1998. Long-run equilibrium real exchange rates and oil prices. Economics Letters 58: $231-238$.

Church KB, Mitchell PR, Sault JE, Wallis KF. 1997. Comparative properties of models of the UK economy. National Institute Economic Review 161: 91-100.

Church KB, Sault JE, Sgherri S, Wallis KF. 2000. Comparative properties of models of the UK economy. National Institute Economic Review 171: 106-122.

Cooley TF, LeRoy SF. 1985. Atheoretical macroeconometrics: a critique. Journal of Monetary Economics 16: $283-308$.

Darby J, Ireland J, Leith C, Wren-Lewis S. 1999. COMPACT: a rational expectations, intertemporal model of the United Kingdom economy. Economic Modelling 16: 1-52.

Evans L, Wells G. 1983. An alternative approach to simulating VAR models. Economics Letters 12: 23-29.

Fisher LA, Huh H-S, Summers PM. 2000. Structural identification of permanent shocks in VEC models: a generalization. Journal of Macroeconomics 22: 53-68.

Garratt A, Lee K, Pesaran MH, Shin Y. 2000. A structural cointegrating VAR approach to macroeconometric modelling. In Econometric Modelling: Techniques and Applications, Holly S, Weale MR (eds). Cambridge University Press: Cambridge; 94-131.

Garratt A, Lee K, Pesaran MH, Shin Y. 2003. A long run structural macroeconometric model of the UK. Economic Journal 113: 412-455.

Gilchrist S, Williams JC. 2000. Putty-clay and investment: a business cycle analysis. Journal of Political Economy 108: 928-960.

Granger CWJ. 1981. Some properties of time series data and their use in econometric model specification. Journal of Econometrics 16: 121-130.

Johansen S. 1991. Estimation and hypothesis testing of cointegration vectors in Gaussian vector autoregressive models. Econometrica 59: 1551-1580.

Johansen S. 1995. Likelihood-Based Inference in Cointegrated Vector Autoregressive Models. Oxford University Press: Oxford.

King RG, Plosser CI, Stock JH, Watson MW. 1991. Stochastic trends and economic fluctuations. American Economic Review 81: 819-840.

Koop G, Pesaran MH, Potter SM. 1996. Impulse response analysis in nonlinear multivariate models. Journal of Econometrics 74: 119-147.

Levtchenkova S, Pagan AR, Robertson JC. 1998. Shocking stories. Journal of Economic Surveys 12: $507-532$.

Copyright $\odot 2005$ John Wiley \& Sons, Ltd.

J. Appl. Econ. 20: 209-228 (2005) 
Lucas RE. 1976. Econometric policy evaluation: a critique. Carnegie-Rochester Conference Series on Public Policy 1: 19-46.

McKibbin WJ, Sachs JD. 1991. Global Linkages: Macroeconomic Interdependence and Cooperation in the World Economy. Brookings Institution: Washington, DC.

Mitchell PR, Sault JE, Smith PN, Wallis KF. 1998. Comparing global economic models. Economic Modelling 15: $1-48$.

Pesaran MH, Shin Y. 1998. Generalized impulse response analysis in linear multivariate models. Economics Letters 58: $17-29$.

Pesaran MH, Shin Y. 2002. Long-run structural modelling. Econometric Reviews 21: 49-87.

Pesaran MH, Smith RP. 1998. Structural analysis of cointegrating VARs. Journal of Economic Surveys 12: 471-505.

Pesaran MH, Shin Y, Smith RJ. 2000. Structural analysis of vector error correction models with exogenous I(1) variables. Journal of Econometrics 97: 293-343.

Pesaran MH, Schuermann T, Weiner SM. 2004. Modeling regional interdependencies using a global errorcorrecting macroeconometric model (with discussion). Journal of Business and Economic Statistics 22: $129-181$

Sims CA. 1980. Macroeconomics and reality. Econometrica 48: 1-48.

Sims CA. 1986. Are forecasting models usable for policy analysis? Federal Reserve Bank of Minneapolis Quarterly Review, Winter: 2-16.

Stock JH, Watson MW. 1988. Testing for common trends. Journal of the American Statistical Association 83: $1097-1107$.

Wallis KF. 1995. Large-scale macroeconometric modeling. In Handbook of Applied Econometrics, Pesaran MH, Wickens MR (eds). Blackwell: Oxford; 312-355.

Wallis KF. 2000. Macroeconometric modelling. In Macroeconomic Policy: Iceland in an Era of Global Integration, Gudmundsson M, Herbertsson TT, Zoega G, (eds). University of Iceland Press: Reykjavik; 399-414.

Wallis KF. 2004. Comparing empirical models of the euro economy. Economic Modelling 21: 735-758.

Wren-Lewis S, Darby J, Ireland J, Ricchi O. 1996. The macroeconomic effects of fiscal policy: linking an econometric model with theory. Economic Journal 106: 543-559. 